\title{
Appropriateness of Antibiotic Use in Enteric fever inpatients in Tertiary Care Hospitals in Western Nepal: A Cross-Sectional Study
}

\author{
Alam $\mathrm{K}^{1}$, Mishra $\mathrm{P}^{3}$, Angsulee $\mathrm{NK}^{2}$
}

${ }^{1}$ Assistant Professor, Department of Pharmacology, Manipal College of Medical Sciences, Pokhara,

Nepal.

${ }^{2}$ Assistant Professor, Department of Social and Administrative Pharmacy, Faculty of Pharmaceutical

Sciences, Chulalongkorn University, Bangkok, Thailand

${ }^{3}$ Professor, Department of Pharmacology, Saba University School of Medicine, Saba, Dutch Caribbean,

Netherlands Antilles.

\section{Section Editor}

Dr. Indrajit Banerjee

\section{Original Article}

\section{Corresponding Author:}

Dr. Kadir Alam PhD

Assistant Professor, Department of Pharmacology,

Manipal College of Medical Sciences, Pokhara, Nepal

E-mail:alamkad2050@yahoo.com

\section{Abstract}

\section{Background:}

Enteric fever, also known as typhoid fever, is a commonly diagnosed disease in Nepal. Globally, enteric fever affects 21.6 million people and causes 216500 deaths annually. Appropriate use of antibiotics is a key element in the successful treatment of enteric fever.

\section{Objective:}

The study was aimed to study antibiotic use and their appropriateness in the patient with Enteric Fever.

\section{Methods:}

A cross-sectional study was carried out in two tertiary-care hospitals viz. Manipal Teaching Hospital (MTH) and Western Regional Hospital (WRH) in western Nepal between Aug-
September 2010. Appropriateness in this study was assessed using Medication Appropriateness Index (MAI) criteria which include indication, effectiveness, dosage, correct directions, practical directions, drug-drug interactions, drug-disease interactions, duplication, duration and expense.

Results:

Mean use of antibiotics in WRH (2.18 \pm 0.87$)$ was not significantly different $(P=0.015)$ from MTH $(2.13 \pm 1.11)$. The Cephalosporin group of antibiotics was used widely to treat enteric fever in both hospitals. On average 1.12 Cephalosporin per patient in MTH and 0.93 Cephalosporin per patient in WRH were used. On average, we found that $31.7 \%$ in MTH and $39.5 \%$ in WRH of patient's treatments with antibiotics were inappropriate. Other common types of inappropriateness are expensive drugs [90\% (MTH), 92\% (WRH)] duplication of antibiotics [53\% (MTH), 822\% $(\mathrm{WRH})]$, prescribing high generation antibiotics [80\% (MTH), 89\% (WRH)], and practical direction [17\% (MTH), 33\% (WRH)].

\section{Conclusion:}

Conclusively, more than thirty percent of patients in both of hospitals treated for enteric fever received inappropriate antibiotics. Hence we recommend future education or managerial intervention to improve appropriateness.

Keywords: Appropriateness, Antibiotic Use, Enteric Fever, Nepal. 


\section{Background}

Enteric fever, commonly known as typhoid fever, is a severe systemic illnesses characterized by sustained fever and abdominal symptoms. Globally, enteric fever causes illnesses to 21.6 million and death to 216500 people every year ${ }^{1}$. The disease is highly epidemic in Asian countries, especially in Nepal, India, Vietnam and Indonesia ${ }^{2}$. Among Asian countries, Kathmandu, the capital city of Nepal is regarded as enteric fever capital of the world ${ }^{3}$. Salmonella typhi and Salmonella paratyphi are regarded as the major causes of the disease in Nepal ${ }^{4}$. Studies from Nepal suggests the emergence of multi-drug resistant isolates and resistance to first line drugs like co-timoxazole, amoxicillin, chloramphenicol and partial resistance to ciprofloxacin and ofloxacin ${ }^{5,6}$. Reasons behind the emergence of antibacterial resistance are unknown. However, it is a well-known fact that antibiotic resistance is an inevitable consequence of irrational use of antibiotics. ${ }^{7,8}$. The availability of antibiotics on an over-the-counter basis in $\mathrm{Nepal}^{9}$ may play a role in the rise of antibiotic resistance. Although there are some studies detailing the emergence of a typhoid epidemic and antibiotic resistance in enteric fever, the number of studies on rational use of antibiotics is deficient.

The Medication Appropriateness Index (MAI) was originally developed by Hanlon et al. in 1992 to assist physicians and pharmacists in assessing the appropriateness of a medication for given patients. It consists of ten purviews: indication, effectiveness, dosage, correct directions, practical directions, drug-drug interactions, drug-disease interactions, duplication, duration and expense. ${ }^{10}$ The present study was conducted to know the appropriateness of antibiotic therapy in the patients with Enteric Fever using Medication Appropriateness Index criteria.

\section{Material and Methods}

\section{Study design: Cross-Sectional}

Study duration: Two months (August 2010 to September 2010) Study site: The study was conducted at Manipal Teaching Hospital (A private tertiary care center) and Western Regional Teaching Hospital (A public tertiary care hospital), which are two tertiary care hospitals in Western Nepal.

Materials: Data collection form and Medication Appropriateness Index (MAI).

Methodology: All data of patients suffering from enteric fever was collected from in-patient file using a data collection form. It included patient demography, history, clinical sign and symptoms, laboratory findings (biochemistry, microbiology, pathology and others), diagnosis, antibiotic therapy along with other concurrent medication (Medicine name, dosage, duration, quantity, direction) etc. Cost of medications was obtained from Hospital Pharmacy Unit.

Assessment of Appropriateness: In this study, we used the MAI criteria to assess the appropriateness of antibiotics therapy. MAI is a validated and reliability tested instrument and was used in several studies evaluating appropriateness ${ }^{10-13}$. It has 10 domains which include indication, effectiveness, dosage, duration, direction, drug-drug interactions, drug-disease interactions, practicality, cost and duplication of therapy. Each domain has its own specific definition. In this study, we have used modified MAl criterion which was devised for evaluating antibiotic prescribing in inpatients by Tayler et al. ${ }^{11}$. Each criterion was defined in terms of Enteric Fever using WHO guideline for Enteric Fever ${ }^{14}$. Appropriate, marginal and inappropriate rating was given to each criterion for each patient.

Study Definition: The study definition of each domain for this study is given below.

1. Indication: Indication in this study was defined based on the sign, symptom, disease, Lab result or condition for which antibiotics were prescribed.

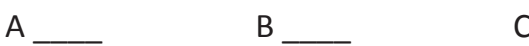

Appropriate Inappropriate Marginal

2. Effectiveness: It was defined based on their sensitivity towards isolated organism and clinical outcome produced.

A

Appropriate Inappropriate Marginal

3. Dosage: It was defined as the total amount of medication administered during period for therapy as per WHO recommended guideline.

A

Appropriate Inappropriate Marginal

4. Direction: Directions in this study was defined as the instructions given for the use of a medication where we assessed the route of administration, relationship to food and liquid, the schedule, and time of the day.

A

Appropriate Inappropriate Marginal

5. Practical: It was defined as capable of being used or being put into practice where we assessed whether the directions for use were practical for the patient adherence.

A

B

c

Practical Marginal Impractical

6. Drug-drug interactions: It was defined as the effect one medication has on another medicine when administered concomitantly. To assess this we used Micromedex 2 healthcare series.

A

B

C

No Interaction Interaction Marginal

7. Drug-disease interaction: It was defined as the effect that the medicine has on a preexisting disease or condition and here we assesses whether the medicine worsened the patient's disease or condition.

A

No Interaction Interaction Marginal 
8. Duplication: Unnecessary duplication was defined as use of 2 medicines from the same chemical or pharmacologic class simultaneously in a manner that is no beneficial effects.

A B C

Necessary

Unnecessary

Marginal

9. Duration: It was defined as the length of therapy. In this study, we assessed the length of therapy that the patient has received according to $\mathrm{WHO}$ guidelines

A

$$
\text { B }
$$$$
\text { C }
$$

Appropriate

Inappropriate

Marginal

10. Expensiveness: In this we assessed the cost of the drug compares to other agents of equal efficacy and tolerability.

A B

C

Least Expensive Marginal

Most Expensive

Sample Size Calculation: Although, the prevalence of enteric fever is higher in Asian countries, it lies between $0.3-1 \%^{1-4}$. The required sample size was then calculated from formula $n=$ $Z^{2} \alpha / 2 P(1-P) / M^{2}$ Where, $M=$ margin of error, $P=$ Prevalence of the characteristic. Thus, the sample size (n) at $95 \%$ confidence interval and $5 \%$ margin of error will be $n=1.962 \times 0.01 \times 0.99$ / $(0.05)^{2}=15.21 \sim 16$ which is very less. Hence, we increased the required sample size up to 100 in each hospital so that we can apply descriptive statistics. So, all patients with enteric Fever treated with antibiotics during the study period were included. Statistics: Discriptive statistics were used to analyse the data using Statistical Package for the Social Sciences (SPSS) for Windows Version 17.0 (SPSS Inc; Chicago, IL, USA).

Ethics: Ethical approval was obtained from the Nepal Health Research Council (NHRC), a national research authority under ministry of health and also permission for research were obtained from institutional research committee of the two study hospitals.

\section{Results}

1. Demography of Patients suffering from Enteric Fever:

The mean age of the patients was $22.81 \pm 20.52$ and 29.13 \pm 17.84 in WRH and MTH respectively (Table 1).

Table 1. Demography of Patients suffering from Enteric Fever

\begin{tabular}{|c|c|c|c|}
\hline Demography & Parameter & WRH & MTH \\
\hline Age & Mean & $22.81 \pm 20.52$ & $29.13 \pm 17.84$ \\
Gender & Female & 45 & 46 \\
& Male & 55 & 54 \\
& Brahman & 54 & 47 \\
& Chhetri & 10 & 22 \\
\hline \multirow{2}{*}{ Races } & Mangolian & 13 & 6 \\
& Newar & 0 & 8 \\
& Others & 15 & 17 \\
\hline \multirow{2}{*}{ Duration of stay } & Missing & 8 & 0 \\
\hline \multirow{2}{*}{ Departments } & Mean & $3.74 \pm 1.58$ & $5.64 \pm 2.34$ \\
& Medicine & 63 & 84 \\
\hline & Pediatrics & 36 & 15 \\
\hline
\end{tabular}

Nepal Journal of Epidemiology 2013;3(1): 236-242

\section{Medicine used in the treatments:}

Altogether, 565 and 796 drugs were used for the treatment of 100 patients from WRH and MTH respectively. Mean number of medicines used in the treatments of WRH (5.80 \pm 2.37$)$ was not statistically different $(P=0.154)$ from MTH (7.91 2.85$)$. Anatomical therapeutic classification (ATC) of prescribed medicine (Fig. 1) suggests antimicrobial class of drugs were highly prescribed in both hospitals.

Figure 1. Anatomical therapeutic classification (ATC) of drug prescribed in Enteric Fever

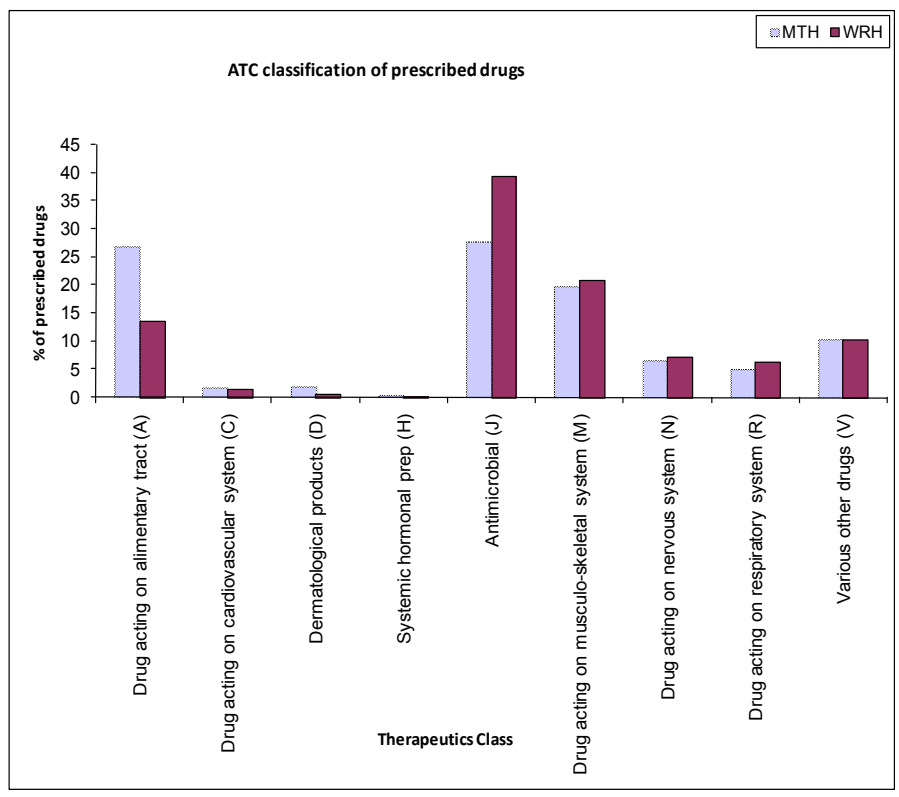

\section{Antibiotic used in the treatment of enteric fever:}

A total of 218 and 213 antibiotics were prescribed in WRH and MTH respectively for the treatment of 100 patients from each hospital (Total 200 Patients). Mean use of antibiotics in WRH (2.18土.87) was not significantly different $(P=0.015)$ from MTH (2.13 \pm 1.11 ). Further, study found that more than $20 \%$ of case was treated with 3 antibiotics in the both hospitals (Fig. 2).

Figure 2 Number of antibiotic used in the treatment

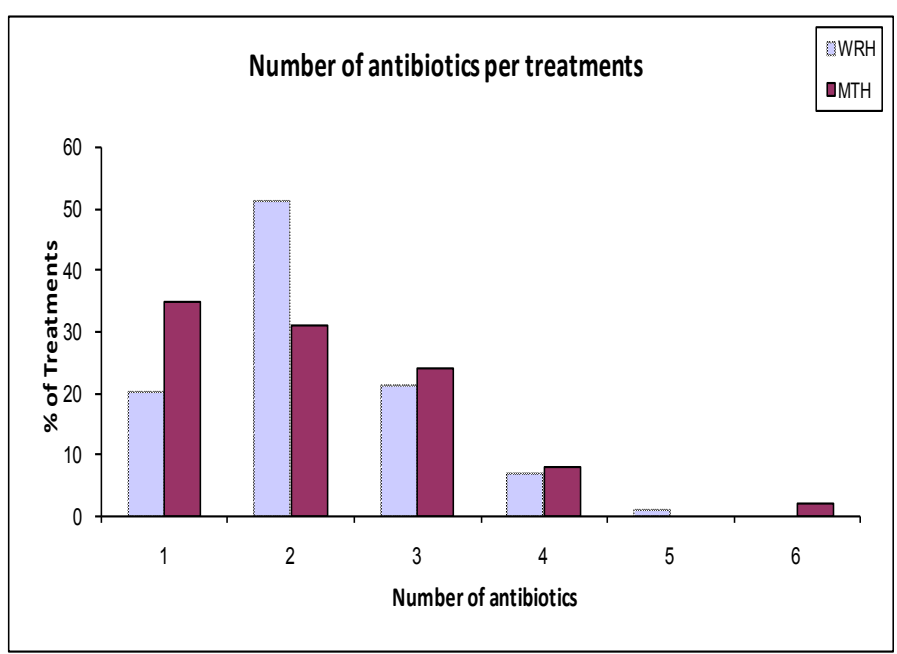




\section{Antibiotics Category:}

This study showed that the Cephalosporin group of antibiotic was used widely to treat enteric fever in both hospitals. On average 1.12 Cephalosporin in MTH and 0.93 Cephalosporin in WRH were used per treatment. The uses of Cephalosporin in two hospitals were not significantly different. Whereas, use of Macrolides in WRH was significantly higher than MTH (Table 2).

Table 2 Category of antibiotics used per treatment

\begin{tabular}{|c|c|c|c|}
\hline Group of Antibiotics & WRH & MTH & P-value \\
\hline Aminoglycoside & $0.33 \pm .47$ & $0.24 \pm .45$ & 0.018 \\
\hline Cephalosporin & $0.93 \pm .38$ & $1.12 \pm .50$ & 0.052 \\
\hline Chloramphenicol & $0.02 \pm .14$ & 0.00 & - \\
\hline Co-amoxyclav & $0.02 \pm .14$ & 0.00 & - \\
\hline Macrolide & $0.54 \pm .50$ & $0.12 \pm .33$ & 0.000 \\
\hline Penicillin & $0.05 \pm .22$ & $0.04 \pm .20$ & 0.497 \\
\hline Fluroquinolone & $0.07 \pm .26$ & $0.27 \pm .57$ & 0.000 \\
\hline Tetracycline & $0.01 \pm .10$ & $0.13 \pm .34$ & 0.000 \\
\hline Miscellaneous & $0.21 \pm .41$ & $0.18 \pm .44$ & 0.418 \\
\hline
\end{tabular}

\section{Resistant pattern of Salmonella:}

Very few samples were taken from patients for doing cultures and sensitivity tests.

Figure 3 Resistance patterns of Salmonella species.

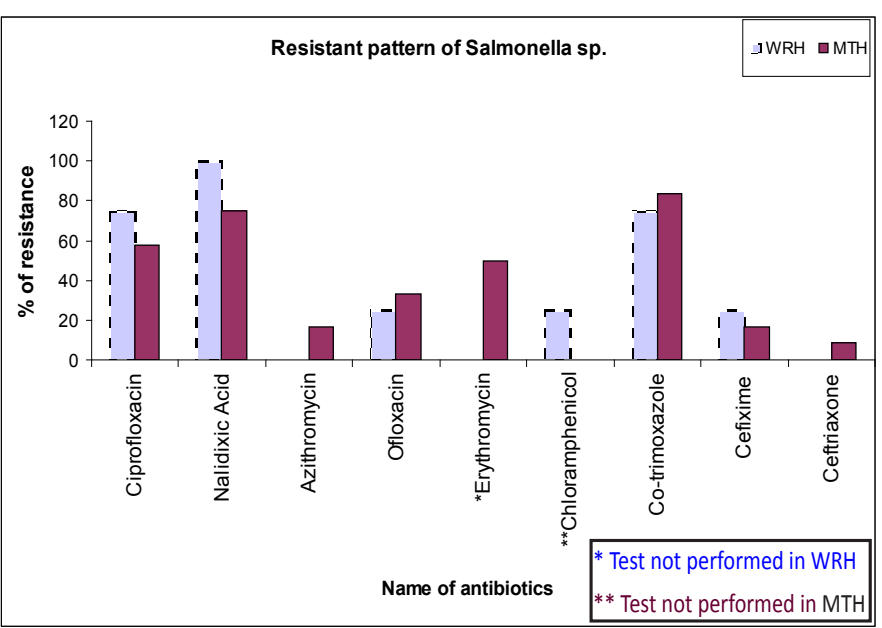

Among the tested sample only 12 sample in MTH and 4 samples in WRH had growths. The resistant pattern showed that Nalidixic Acid and Co-timoxazole were more than $80 \%$ resistance in both hospitals whereas Ciprofloxacin were more than $50 \%$ resistant in both the hospitals. (Fig.3).

\section{Cost of treatment of enteric fever:}

The mean cost of medication in enteric fever treatment in MTH and WRH was not significantly different. Similarly the mean costs of antibiotics in enteric fever treatment in both the hospitals were not statistically significant. The detail of cost is given in Table 3.

Table 3 Mean cost of per treatment of enteric fever in two hospitals

\begin{tabular}{|c|c|c|c|}
\hline Parameter & WRH & MTH & $P$-value \\
\hline $\begin{array}{c}\text { Mean cost of } \\
\text { prescribed Medication }\end{array}$ & $1428.98 \pm 1178.35$ & $2279.07 \pm 1533.49$ & 0.029 \\
\hline $\begin{array}{c}\text { Mean cost of } \\
\text { Antibiotics }\end{array}$ & $1228.49 \pm 840.28$ & $1523.86 \pm 1054.19$ & 0.422 \\
\hline $\begin{array}{c}\text { Percentage of } \\
\text { Antibiotic Cost }\end{array}$ & 86 & 67 & - \\
\hline
\end{tabular}

\section{Possible drug-drug interaction:}

The drug-drug interactions among the prescribed medicine were evaluated using Micromedex. There were drug-drug interactions in around $11 \%$ of patients prescribed medication. Some common drug-drug interactions are given in Table 4.

\section{Appropriateness of treatments:}

The appropriateness analysis of the treatment of enteric fever patients was done using Medication Appropriateness Index (MAI) 10 points indicators (Table 5) and each indicator was evaluated by researcher using WHO guidelines ${ }^{14}$ asillustrated in methodology. While assessing we found that majority of indications were inappropriate based on WHO guidelines.

Table 4. Common drug-drug interactions

\begin{tabular}{|c|c|c|c|c|c|c|}
\hline Drug & Drug & Interaction & Severity & Docum-entation & WRH & MTH \\
\hline Amikacin & Furosemide & $\begin{array}{l}\text { Concurrent use may result in increased amikacin } \\
\text { plasma \& tissue concentrations \& additive } \\
\text { ototoxicity and/or nephrotoxicity }\end{array}$ & Major & Fair & $\sqrt{ }$ & $\sqrt{ }$ \\
\hline Ketorolac & Norfloxacin & $\begin{array}{c}\text { Concurrent use may result in an increased risk } \\
\text { of seizures }\end{array}$ & Moderate & Fair & $\sqrt{ }$ & - \\
\hline Ampicillin & Pantoprazole & $\begin{array}{l}\text { Concurrent use may result in loss of ampicillin } \\
\text { efficacy }\end{array}$ & Moderate & Fair & $\sqrt{ }$ & $\sqrt{ }$ \\
\hline Antacid & Ciprofloxacin & $\begin{array}{l}\text { Concurrent use may result in decreased } \\
\text { ciprofloxacin effectiveness }\end{array}$ & Moderate & Good & - & $\sqrt{ }$ \\
\hline Ciprofloxacin & Diclofenac & $\begin{array}{l}\text { Concurrent use may result in increased } \\
\text { ciprofloxacin plasma concentrations }\end{array}$ & Moderate & Excellent & - & $\sqrt{ }$ \\
\hline Doxycycline & Ferrous sulphate & $\begin{array}{l}\text { Concurrent use may result in decreased } \\
\text { tetracycline and iron effectiveness. }\end{array}$ & Moderate & Good & - & $\sqrt{ }$ \\
\hline
\end{tabular}

Nepal Journal of Epidemiology 2013;3(1): 236-242 
Table 5 Appropriateness analysis for Enteric Fever Treatment ( $n=100$ / hospital)

\begin{tabular}{|c|c|c|c|c|c|c|}
\hline \multirow[t]{2}{*}{ Criterion } & \multicolumn{2}{|c|}{ Appropriate } & \multicolumn{2}{|c|}{$\begin{array}{l}\text { Marginally } \\
\text { appropriate }\end{array}$} & \multicolumn{2}{|c|}{ Inappropriate } \\
\hline & MTH & WRH & MTH & WRH & MTH & WRH \\
\hline Indication & 12 & 4 & 8 & 7 & 80 & 89 \\
\hline Effectiveness & 12 & 1 & 44 & 47 & 44 & 52 \\
\hline Correct dosage & 95 & 98 & 1 & 1 & 4 & 1 \\
\hline Correct direction & 95 & 97 & 2 & 0 & 3 & 3 \\
\hline $\begin{array}{l}\text { Drug-drug } \\
\text { interactions }\end{array}$ & 89 & 89 & 0 & 1 & 11 & 10 \\
\hline $\begin{array}{l}\text { Drug-disease } \\
\text { interaction }\end{array}$ & 100 & 100 & 0 & 0 & 0 & 0 \\
\hline $\begin{array}{l}\text { Practical } \\
\text { directions }\end{array}$ & 65 & 45 & 18 & 22 & 17 & 33 \\
\hline $\begin{array}{l}\text { Least expensive } \\
\text { alternative }\end{array}$ & 7 & 7 & 3 & 1 & 90 & 92 \\
\hline $\begin{array}{l}\text { Duplication with } \\
\text { other drug }\end{array}$ & 46 & 18 & 1 & 0 & 53 & 82 \\
\hline $\begin{array}{c}\text { Duration of } \\
\text { therapy }\end{array}$ & 75 & 50 & 10 & 17 & 15 & 33 \\
\hline Average Score & 59.6 & 50.9 & 8.7 & 9.6 & 31.7 & 39.5 \\
\hline
\end{tabular}

\section{Discussion:}

\section{Demography patients with enteric fever:}

Enteric fever is highly prevalent in Asian Sub-continent. In this study, the mean age of the patients suffering from enteric fever in two hospitals were $22.81 \pm 20.52$ and $29.13 \pm 17.84$ in WRH and $\mathrm{MTH}$ respectively which is similar to studies conducted by Karkey et al. (higher in age group between 15-30 years) in Kathmandu and Sharma et al. (28.33 \pm 15.2 )in Dhulikhel, Nepal ${ }^{4,15}$.

However, another study conducted by Malla et al. in Kathmandu found higher prevalence in children (35\% in age group 0-9 and $31.8 \%$ in $10-19$ years $)^{16}$.

We found enteric fever was more prevalent in males $154 \%$ in MTH and $55 \%$ in WRH) in data from both hospitals, which is similar to study conducted by Malla et al. (64\%), and Bhatta et al. in Kathmandu. Another study from Nigeria conducted by Zailani SB et al has a similar finding without any satisfactory explanation ${ }^{16,17,18}$. Enteric fever in this study was more prevalent in Brahmin races in both of the hospitals (54\% in WRH and $47 \%$ in $\mathrm{MTH}$ ). A study conducted by Pokharel et al. in Kathmandu also found more number of cases in the Brahmin-Chhetri group $(46 \%)^{6}$. However, Annual Morbidity Report 2005 of Center for Disease Control found all case among Asians, and Latinos compared to no cases in Blacks and Whites ${ }^{19}$.

\section{Duration of Hospital Stay:}

Outcomes in the treatment of enteric fever were described as excellent in a European study ${ }^{20}$. The duration of the given treatment varied from person to person, and was based on the type of antibiotic therapy. In our present study, the mean duration of hospital stay was $3.74 \pm 1.58$ in WRH and 5.64 \pm 2.34 in MTH. However, in a study conducted by Walia et al. in India found the duration of stay in the hospital to be around 8.2-12.1 with different treatment regimens and another study conducted by Farmakiotis $D$ et al. in travelers found that the median duration of hospital stay was 7 days $^{21,22}$.

\section{Medicines Used in the Treatment:}

Antibiotics remain the mainstay of treatment of enteric fever. Other medicines are merely symptomatic treatment. In our study, other concurrent medicines used were drugs used in GIT, drugs used in skeleton-muscular system, drug used on nervous system etc. Although we did not find a similar study on concurrent medication in enteric fever, a study conducted by Sharma et al. in Dhulikhel found common symptoms like fever, headache, chills, vomiting, cough, pain abdomen, diarrhea, constipation and disorientation which suggests the use of above mentioned class of drugs ${ }^{15}$. A review article on management of typhoid fever advocates use of tepid baths and sponging rather than use of NSAID ${ }^{23}$.

\section{Appropriateness of Antibiotics}

Therapy: Appropriate use of antibiotics is the key element in the treatment all bacterial infections. We assessed the appropriateness of antibiotic therapy using MAl criteria. On average, $31.7 \%$ in $\mathrm{MTH}$ and $39.5 \%$ in $\mathrm{WRH}$ of patients with prescribed antibiotics were inappropriate which is comparatively lesser than found in a study conducted by Tobia et $\mathrm{al}^{13}$ in the US, where around two-thirds of patients received at least one inappropriate antibiotic and Tobgay et al 24 in Bhutan where around 44\% patients received inappropriate antibiotics. The lesser incidence of inappropriateness in our study may be because our study was conducted on in-patients whereas these two studies were conducted on the out-patients with respiratory tract infection in Tobia et al. and in overall out-patients in Tobgay et al. study. In our study we found that common type of inappropriateness includes the duplication of antibiotics, expensiveness, prescribing high generation antibiotics, and practical directions. There were similar findings in terms of expensiveness from Tobia et al. ${ }^{13}$ in US but differs in terms of dose, duration and indication where it was more appropriate. Likewise, Tobgay et al. $\mathrm{al}^{15}$. in Bhutan found similar inappropriateness with expensiveness, prescribing higher generation antibiotics, dose and practical direction but differed in terms of duration of therapy where it was more appropriate. According to draft of national antibiotic treatment guidelines of Nepal, enteric fever should be treated with single antibiotic and there are similar recommendation from WHO guidelines and guidelines from Indian Ministry of Health and Family Welfare ${ }^{14,25,26}$. However, in this study, mean number of antibiotics for the treatment of enteric fever were 2.18土.87 
in $\mathrm{WRH}$ and $2.13 \pm 1.11$ in $\mathrm{MTH}$ which was not significantly different $(P=0.015)$. These suggest the overuse of antibiotics in the treatment of enteric fever in both of the hospitals. WHO guidelines for the treatment of enteric fever advocates the use of fluoroquinolone as first line therapy even in severe enteric fever ${ }^{14}$. In contrast, majority of patients from either hospital received Ceftriaxone as first line therapy in the present study indicating indiscriminate use of newer generation antibiotics.

\section{Conclusion}

Our founding suggests that more than thirty percent of patients in both hospitals treated for enteric fever received inappropriate antibiotics. Expensiveness, prescribing higher generation antibiotics and duplication with antibiotics were common types of inappropriateness. It is well known fact that inappropriate use of antibiotic leads to antibiotic resistance, so such practice needs to be discouraged. Hence, we believe that this study will help in planning and determining types of intervention and we recommend future educational and managerial interventions to improve appropriateness.

\section{Limitation of the study}

Due to unavailability of established hospital guidelines, we have used WHO guidelines to assess the appropriateness, and is the main limitation of this study.

\section{Future scope of study}

An interventional study using local established guideline will be helpful in increasing appropriateness of drug therapy.

\section{Acknowledgment}

The authors acknowledge Mr. Anil Kumar Sah, Lecturer, CCT College, Butwal, Nepal for his whole hearted support and help in this study.

\section{Authors' contributions}

All the authors in this contributed equally in designing this study to preparing the manuscript. All authors have gone through the manuscript and approved the same for publication.

\section{Conflict of Interests:}

The authors do not have any conflict of interest arising from the study.

\section{What this study adds:}

This study will provide an idea of determining appropriateness. Further it will help in planning and determining type of intervention to increase appropriateness of drug therapy.

\section{References}

1. Crump JA, Luby SP, Mintz ED. The global burden of typhoid fever. Bull World Health Organ 2004; 82: 346-53.

2. Kothari A, Pruthi A, Chugh TD. The Burden of Enteric Fever. JInfect Developing Countries 2008; 2(4): 253-9.

3. Karkey A, Aryjal A, Basnyat B, Baker S. Kathmandu, Nepal: Still an enteric fever capital of the world. JInfect Developing Countries 2008; 2(6): 461-5.

4. Karkey A, Arjyal A, Anders KL, Boni MF, Dongol S, et al. The Burden and Characteristics of Enteric Fever at a Healthcare Facility in a Densely Populated Area of Kathmandu. PLoS ONE 2010; 5(11): e13988. doi:10.1371/journal.pone.0013988.

5. Shakya KN, Baral MR, Shrestha R. Current Pattern in Antimicrobial Susceptibility in Enteric Fever in Nepali Children. PMJN 2008; 8(1).

6. Pokharel P, Rai SK, Karki G, A Katuwal, Vitrakoti R et al. Study of enteric fever and antibiogram of Salmonella isolates at a Teaching Hospital in Kathmandu Valley. Nepal Med Coll J 2009; 11(3): 176-178.

7. McGowan JE. Is antimicrobial resistance in hospital microorganisms related to antibiotic use? Bull. N. Y. Acad. Med. 1987; 63(3): $253-68$.

8. Wood AJJ. Antimicrobial-drug resistance. NEJM 1996; 335 (19): 1445-53.

9. Wachter DA, Joshi MP, Rimal B. Antibiotic dispensing by drug retailers in Kathmandu, Nepal. Tropical Medicine and International Health 1999; 4(11): 782-8.

10. Hanlon JT, Weinberger M, Samsa GP, Schmader KE, Uttech $\mathrm{KM}$, Lewis IK et al. A randomized, controlled trial of a clinical pharmacist intervention to improve inappropriate prescribing in elderly outpatients with poly-pharmacy. Am J Med 1996;100 (4): 428-37.

11. Taylor CT, Stewart LM, Byrd DC, Church CO. Reliability of an instrument for evaluating antimicrobial appropriateness in hospitalizedpatients. Am J Health Syst Pharm. 2001;58:242246.

12. Miller SW, Warnock R, Marshall LL. Appropriateness of antibiotic prescribing for urinary tract infections in long-term care facilities. Consult Pharm. 1999;14:157-77.

13. Tabia CC, Aspinall SL, Good CB, Fine MJ, Halon JT. Appropriateness of Antibiotic Prescribing in Veterans withCommunity-Acquired Pneumonia, Sinusitis, or 
AcuteExacerbations of Chronic Bronchitis: A Cross-Sectional Study. Clin Ther. 2008;30:1135-44.

14. World Health Organization 2003. Background document: The diagnosis, treatment and prevention of typhoid fever. WHO/V\&B/03.07.

15. Sharma N, Koju R, Karmacharya B, Tamang MD, Makaju R et al. Typhoid fever in Dhulikhel Hospital, Nepal. Kathmandu University Medical Journal 2003; 3 (7): 188-92.

16. Malla S, Kansakar P, Serichantalergs, Rahman M, Basnet S. Epidemiology of typhoid and paratyphoid fever in Kathmandu: two years study and trends of antimicrobial resistance. JNMA 2005; 44: 18-22.

17. Bhatta CP, Bhuyan KC, Maharjan A. Antibiotic Sensitivity Pattern of Salmonella Species Isolated from Blood Culture. Journal of Nepal Health Research Council 2005; 3 (2): 35-8.

18. Zailani SB, Aboderin AO, Onipede AO. Effect of socioeconomic status, age and sex on antibody titre profile to Salmonella typhi/paratyphi in Ile-Ife, Nigeria. Niger J Med. 2004; 13(4): 383-7.

19. Acute Communicable Disease Control. 2005 Annual Morbidity Report. Assessed on 15th June 2010 (available on http://www.ph.lacounty.gov/acd/reports/annual/cd05/ typhoid\%20fever\%20acute\%2005.pdf).

20. Ispahani P, Slack RCB. Enteric Fever and Other Extra-intestinal Salmonellosis in University Hospital, Nottingham, UK, Between 1980 and 1997. Eur J Clin Microbiol Infect Dis 2000; 19: 679-87.

21. Walia M, Gaind R, Mehta R, Paul P, Aggarawal P et al. Current perspectives of enteric fever: a hospital-based study from India. Annals of Tropical Paediatrics: International Child Health 2005; 25 (3): 161-74.

22. Farmakiotis $D$, Varughese $J$, Sue $P$, Andrews $P$, Brimmage $M$ et al. Typhoid Fever in an Inner City Hospital: A 5-Year Retrospective Review. Journal of Travel Medicine 2013; 20(1): 17-21.

23. Kalra SP, Naithani N, Mehta SR, Swamy AJ. Current Trends in the Management of Typhoid Fever. MJAFI 2003; 59: 130-35

24. Tabgay T, Tandin, Rai M, Hansen JA, Johansen MV et al. Prescribing pattern of higher antibiotic in the out-patient setting in Bhutan hospitals. Asian Biomed 2010; 4 (2): 349-53.

25. Alliance for the Prudent Use of Antibiotics (APUA)-Nepal. National Antibiotic Treatment Guidelines (Draft).
26. Standard Treatment Guideline for Enteric Fever. Assessed on 15th June 2010 (available on http://mohfw.nic.in)

Article Information

\section{Article history}

\section{Received}

15 February 2012

Received in revised form

24 March 2012

Accepted

04 May 2012 